\title{
Identifying the footprints of global climate modes in time-variable gravity hydrological signals
}

\author{
Christopher E. Ndehedehe $^{\mathrm{a}}$, Vagner G. Ferreira ${ }^{\mathrm{b}}$ \\ ${ }^{a}$ Australian Rivers Institute and Griffith School of Environment \&3 Science, Griffith University, Nathan, \\ Queensland 4111, Australia. \\ ${ }^{b}$ School of Earth Sciences and Engineering, Hohai University, Nanjing, China
}

\section{Abstract}

Modelling continental freshwater dynamics is expected to be challenging in regions with considerable influence of multi-scale global climatic drivers. An assessment of the interplay between these climatic drivers (e.g., El-Niño Southern Oscillation-ENSO) that influence hydro-climatic conditions and hydrological processes is therefore required to optimize predictive frameworks. The main aim of this study is to assess the impacts of eleven key climate modes describing oceanic variability in the nearby oceans on the spatial and temporal distributions of terrestrial water storage (TWS) derived from Gravity Recovery and Climate Experiment (GRACE) (2002 - 2017) over South America (SA). Considering that SA accounts for nearly one fifth of global continental freshwater discharge, this assessment is crucial because of the differences in the intrinsic response of freshwater availability in some regions to several important processes of inter-annual variability. The novel integration of independent component analysis with parameter estimation techniques in this study shows that climate variability drivers (ENSO; Southern Oscillation Index-SOI; Pacific Decadal Oscillation-PDO; Ninos 1+2, 3.0, 3.4 and 4.0; North Tropical Atlantic-NTA and the Caribbean Sea Surface Temperature (SST) anomalies) have considerable association $(\alpha=0.05)$ with GRACE-derived TWS over SA. The influence of Nino $4.0(r=-0.72)$, Nino $3.4(-0.68)$, Nino $3.0(-0.53)$, ENSO $(r=-0.71)$, PDO $(r=-0.69)$, SOI $(r=0.64)$, Caribbean SST $(r=-0.67)$, and NTA $(r=-0.51)$ on TWS are relatively stronger in tropical SA (Amazon basin/northern SA) and result in higher amplitudes of TWS (> $100 \mathrm{~mm})$. Given the temporal and spatial relationships of TWS with PDO over SA, there is also evidence to suggest strong multi-decadal variability in TWS.

Keywords: Amazon basin, GRACE, PDO, Pacific SST, ENSO, North Tropical Atlantic

\footnotetext{
${ }^{*}$ Corresponding author

Email address: c.ndehedehe@griffith.edu.au (Christopher E. Ndehedehe)
} 


\section{Introduction}

The warming of the climate system and other multiple forms of human stressors (e.g., deforestation, land use changes, etc.) affect natural systems, leading to accelerations in the global hydrological cycle.(e.g., 48, 84, 27). Significant changes in the various components of the hydrological cycle are induced by anthropogenic emissions of greenhouse gases (GHG), which alter the radiative equilibrium of the atmosphere leading to considerable rise in temperature (e.g., 24). In other words, GHG emissions are the key drivers of global warming, which in turn could provide major constraint on freshwater availability. For instance, as the climate warms, the hydrological cycle accelerates, causing a rise in the variability, duration and intensity of extreme events (e.g., droughts). This increase have implications that could affect the sustainability of water resources and alter the variability of hydrological regimes (e.g., 48, 24). Identifying the coupled relationship between land water storage and the surrounding oceans, is therefore significant to assessing multi-scale climatic influence on continental hydrology (e.g., 51). Given that these oceans are the key producers of large-scale mesoscale convective systems, and other climate variability drivers (e.g., El-Niño Southern OscillationENSO) that influence meteorological processes and induce extreme hydro-climatic conditions, their impacts on hydrological systems and water resources are undeniable.

The scientific awareness of the rapid changes in global atmosphere and hydrological cycle driven by the influence of climate oscillations and indices of oceanic variability (see, e.g., $7,28,42)$ triggered some concerns on the impacts of climate teleconnections on terrestrial hydrology in general (e.g., 55, 52, 15, 38, 58, 65, 33). These few studies, which are rather limited in scope are indications warranting further diagnostics studies on the role of global climate on land water storage, especially for regions with increased susceptibility to the impacts of climate variability. A recent empirical analyses of global freshwater availability (60) converge with other reports on the composite influence of climate variability and human activities on changes in global freshwater resources (e.g., 53, 66, 37). Some new evidence nonetheless, suggest the influence of global climate will fundamentally continue to amplify freshwater scarcity and variability in some regions (e.g., 5, 53, 49, 12, 3, 67).

Since its inception, the Gravity Recovery and Climate Experiment (GRACE, 71) satellite mission has given an unparalleled perspective to global terrestrial hydrology by providing quantitative estimates of monthly changes in terrestrial water storage (TWS-soil moisture; groundwater; surface water-lakes, rivers, wetlands; snow; and canopy) over large spatial scales (e.g., 48). Considering that strong ocean-land atmosphere interaction and the nearby oceans 
produce the systems that regulates precipitation, which in turn impacts on continental TWS, assessing multi-scale climatic influence on continental hydrology is significant to modelling the influence of threats to freshwater availability and food security (e.g., 60, 76). However, limited ground observations and the lack of a suitable modelling framework are some key constraints to such assessments. Whereas investigating the utility of GRACE as an efficient tool to quantify the influence of global climate modes on continental freshwater dynamics is unarguably essential, such assessment has become necessary for South America (SA), which accounts for nearly one fifth of global continental freshwater discharge (e.g., 38).

As the physical mechanisms behind extreme precipitation for some regions are significantly different from others, the assessment of climate teleconnection induced TWS at the global scale (e.g., 55, 58) would be insufficient to reveal the intrinsic response of specific regions to indices of oceanic variability that drives TWS considerably. Given that mesocale convective systems and other atmospheric mechanisms that drive precipitation differ for some regions, we argue that the nature of impacts and number of global climate modes that induces variations in TWS could differ across climatic regions (e.g., 5, 52, 3). Thus, its seems logical and more efficient to assess the influence of these multiple climate modes on TWS variations on a localised spatial scale (basin or regional). This perhaps was one of the basis for the study by Linage et al. (38) who examined the relationship of seven climate modes with a 10-year GRACE data over the Amazon basin and environs. But considering that some climate oscillations, e.g., ENSO have relatively large asymmetric amplitude variations with energy ranging from 3-5 years, only very limited cycles will occur in 10-years. However, even with an extended GRACE observations (15 years), to date, no study has assessed the impacts of global teleconnections and sea surface temperature (SST) products of the surrounding oceans (Atlantic, Pacific, and Caribbean) on TWS over the entire SA. Such assessment is required to improve our contemporary understanding of the climatic processes that governs inter-annual variations of continental land water storage in the world's most humid region. Apart from leveraging on extended GRACE data, this study highlights a new statistical framework to enhance the assessment of climate impacts on GRACE-derived TWS.

In this study, the main aim is to assess the impacts of key climatic drivers on the spatial and temporal distributions of GRACE-derived TWS (2002-2017) over SA. To this end, a novel twostep regularization approach that integrates multiple linear regression (MLR) and cumulant statistics (e.g., 48, 50, 10) is employed to assess the impacts of these climate modes (climatic drivers) and quantify their contributions on continental TWS. These climatic drivers are based 
on eight prominent SST products of the nearby oceans (i.e., Nino 1+2, Nino 3.0, Nino 3.4, Nino 4, North Tropical Atlantic-NTA, East Tropical Atlantic-ETA, South Tropical Atlantic-STA, and Caribbean) and three global climate teleconnections (e.g., Southern Oscillation IndexSOI and Pacific Decadal Oscillation-PDO; and ENSO). The hypothesis here is that strong ocean-land atmosphere interaction and the nearby oceans produce the systems that regulate precipitation, which in turn impacts on continental TWS. Except for some regions where human water abstraction and land use change drive hydrology, in general, this is the case for most tropical systems where changes in precipitation regulates dynamics in land water storage (e.g., 49, 60, 22, 17). More details about these datasets and methodological development are described in Sections 3 and 4.

\section{Study region}

Due to its unique hydrological and hydrodynamic characteristics, South America (SA) is quite an interesting continent. SA is one the most physiographically diverse wet-dry tropics that is characterised by numerous aquifer types, highlands, lowlands, and highly-productive watersheds (e.g., 21). The continent is home to extremely wet river basins (Amazon river basin) and considerably drier regions where geodetic perturbations and the impacts of other physical processes such as earthquakes and land subsidence have been reported $(19,21,45)$. Some of the major hydro-goelogical river basins and physiographic domains within South American are indicated in Figs. $1 \mathrm{a}$ and b. Apparently, water availability is high in tropical river basins of SA (e.g., Amazon, Orinoco, Magdalena) and shows considerable distribution of annual precipitation as opposed to other regions (Fig. 1a). Although about $12 \%$ of the world's available freshwater is found in the tropical SA basins, which also accounts for approximately $20 \%$ of global freshwater discharge (e.g., 21), population in the arid regions (e.g., north-east Brazil) however, are most often plagued with water scarcity because of limited rainfall (Fig. 1a) and frequent extreme hydrological drought conditions (e.g., 19). Rainfall patterns in SA are largely regulated by atmospheric circulation patterns and the intertropical convergence zone, which defines the seasonal behaviour of precipitation in much of the tropical wet-dry climatic belts. The study by Lu and Dong (40) also highlights the important role of sea surface temperature of the surrounding oceans on rainfall variability in this region. Similar to other highly productive freshwater ecosystems, rainfall drives TWS and changes in water fluxes in the tropical regions of SA (e.g., 49, 60). That is, areas that receive more annual rainfall are likely to experience stronger amplitudes and changes in TWS. For example, mean 
annual precipitation in the Amazon basin is about $4500 \mathrm{~mm}$ (Fig. 1a) and show a rise in TWS during the same period owing to precipitation induced-exchange of fluxes within the floodplain corridors (Fig. 1b). But this is different for the water-deficit regions of north-east Brazil were TWS show significant decline (Figs. 1a-b). Generally, changes in land water storage (Fig. 1b) over SA during the $2000-2017$ period is the aftermath of several factors, including recovery from previous dry period, impacts of global warming on the continent, geodetic disturbances, and perturbations of the nearby oceans, human water developments, among other drivers. (e.g., 21, 60, 30, 38, 34).

(a)

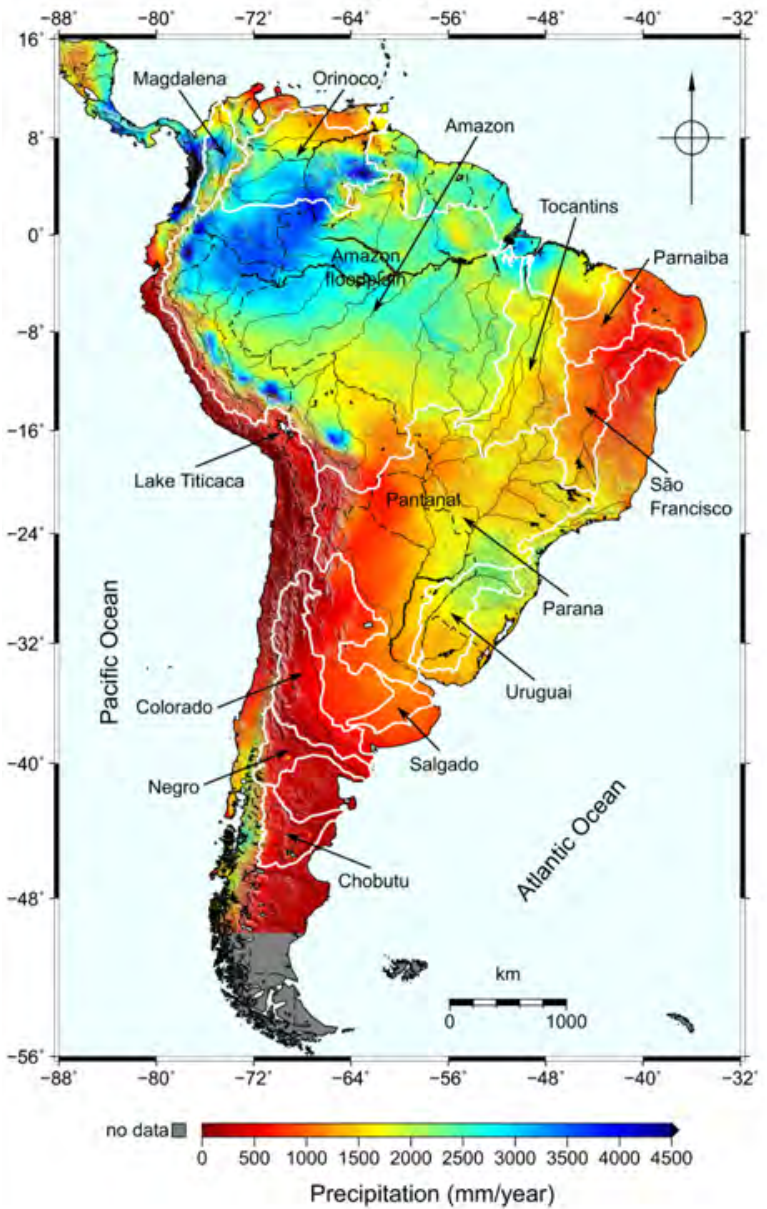

(b)

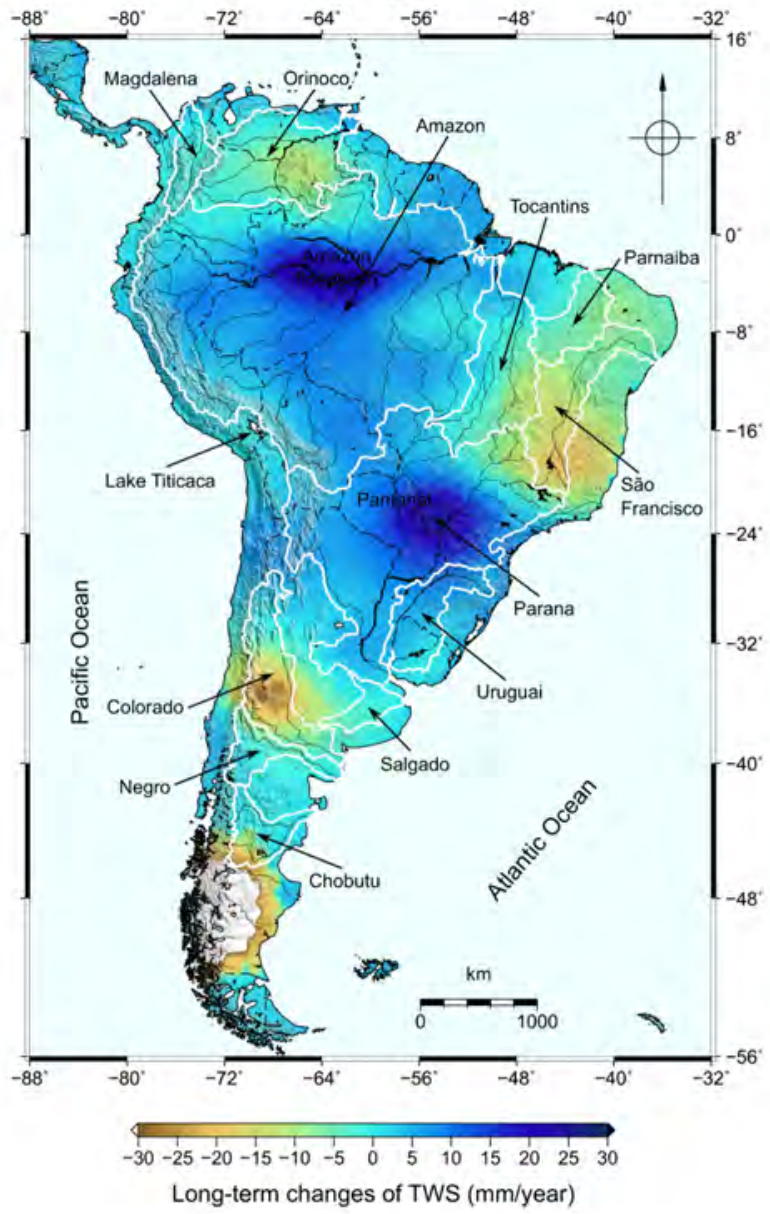

Figure 1: Study region showing major river basins in South America and the nearby oceans. (a) spatial distribution of mean annual rainfall and (b) spatial patterns of trends in observed GRACE-derived terrestrial water storage during the $2002-2017$ period. The computed annual rainfall was accumulated from the Tropical Rainfall Measuring Mission satellite-based precipitation during the 2003 - 2016 period. 


\section{Data}

\subsection{Land water storage assessment using GRACE}

The applications of GRACE data in hydro-climatic research globally is growing and well documented (e.g., 19, 1, 74, 50, 26, 85, 72, 73). The GRACE mascon solutions used in this study solves for monthly gravity field variations in terms of $120 \mathrm{~km}$ wide mascon block totaling 40,692 equal-area geodesic grid tiles $(63,83,79)$ and was accessed from the Center for Space Research (CSR) at The University of Texas through its data portal (http://www2.csr.utexas.edu/ grace/RL05_mascons.html). The final CSR mascon solution is represented on a 0.5 arc-degree resolution, which helps to better the sampling of TWS within a river basin despite its native solution being equivalent to a quadrangle of approximately $120 \times 120 \mathrm{~km}$. Nevertheless, this "high-resolution" mascon solution is limited by the nature of GRACE measurements which is somewhat close to $340 \mathrm{~km}$. The use of GRACE mascons offers the opportunity to implement geophysical constraints with ease, which in turn help to filter out stripes in the maps of TWS, which is presented in the solutions based on the unconstrained Level 2 GRACE data (e.g., 83). Leakage correction for the TWS regarding the CSR mascon solutions were not applied since the mascon blocks lying in both land and ocean do not impact the main river basins over South America. Furthermore, the TWS signal is well contained within the South America's coastline domain. For other regions however, that might not be the case and filter schemes like the Coastline Resolution Improvement filter could be necessary (e.g., 83) or a $120 \mathrm{~km}$ extension in the basin's domain towards the ocean (e.g., 63). More details regarding the derivation of the mascon solution and its performance metrics have been documented in Save et al. (63). Ultimately, the availability of these pre-processed GRACE product simplifies the use of GRACE TWS observations for hydrological applications by hydrologists and other Earth scientists.

\subsection{Sea surface temperature products and teleconnections}

The sea surface temperature (SST) products used in this study include, Ninos $1+2(0-10 \mathrm{~S}$, 90W-80W), 3.0 (5N-5S, 150W-90W), 3.4 (5N-5S, 170W-120W), and 4.0 (5N-5S, 160E-150W). Other SST products are those of the Atlantic ocean (North Tropical Atlantic-NTA, East Tropical Atlantic-ETA, South Tropical Atlantic-STA) and the Caribbean. These products are normalised monthly means from 2002 to 2017 (corresponding to the GRACE period) and are freely available online (https://www. esrl noaa.gov/psd/forecasts/sstlim/atlantic_ indices.html). The ENSO (El-Niño Southern Oscillation) data used in this study describes 
the presence of abnormally warm (El-Niño) and cold (La-Niña) sea surface temperature anomalies in the eastern Pacific and was downloaded from National Oceanic and Atmospheric Administration's (NOAA) data portal (http://www.esrl.noaa.gov/psd/enso/mei/). ENSO is a quasi-periodic oscillation of strong atmospheric coupling in the eastern and near-equatorial Pacific Ocean that is usually characterised by considerable fluctuations in ocean temperature in the tropics and complex teleconnections across the globe (25). In the tropical north-eastern sections of South America, reduced precipitation are associated with the El-Niño phase (e.g., 14). Given that different types of ENSO exhibit several dynamics and teleconnections with rainfall patterns (e.g., 14, 32), we chose the aforementioned SST products to represent the influence of nearby tropical oceans on land water storage anomalies over South America.

The PDO (Pacific Decadal Oscillation) and SOI (Southern Oscillation Index) are other climate teleconnections used in this study and are available on NOAA's website (https:// Www.ncdc.noaa.gov/teleconnections). All these climate oscillations have been normalised similar to the SST products. PDO is a long-lived El-Niño-like pattern of Pacific climate variability with extremes marked by widespread fluctuations in the Pacific Basin and the North American climate (https://www.ncdc.noaa.gov/teleconnections/pdo/). It is an irregular oscillation characterised by low frequency variability, and could be useful for prospective future climate outlook (e.g., 51). The SOI on the other hand, is a measure of observed large-scale variations in air pressure occurring between the western and eastern tropical Pacific during El-Niño and La-Niña episodes. In order words, it is the atmospheric component of ENSO and basically serves as an indicator for the development and intensity of El-Niño and La-Niña events in the Pacific Ocean. Extended periods of negative (positive) SOI values coincide with abnormally warm (cold) ocean waters across the eastern tropical Pacific typical of El-Niño (La-Niña) episodes. The study by Salisbury and Wimbush (62) has demonstrated that the dynamics of ENSO are adequately captured in the SOI observations, making it useful in the prediction of ENSO episodes.

\subsection{Satellite precipitation}

The Tropical Rainfall Measuring Mission (TRMM 3B43) (36) based precipitation covering the same period $(2002-2017)$ as GRACE-TWS was used in this study to identify regions in South America that are vulnerable to the impacts of teleconnections. The monthly TRMM $3 \mathrm{~B} 43$ data with a spatial resolution of $0.25^{\circ} \times 0.25^{\circ}$ has a global coverage $\left(50^{\circ} \mathrm{S}\right.$ and $\left.50^{\circ} \mathrm{N}\right)$ and represents reliable precipitation estimates across the globe. This data can be accessed at the 
National Aerospace and Space Administration (NASA) Goddard Space Flight Center (GSFC) website (http://disc.gsfc.nasa.gov/datacollection/TRMM3B43-V7.shtml).

\section{Method}

\subsection{Assessing climatic influence on terrestrial water storage}

\subsubsection{Deseasonalization of terrestrial water storage}

To assess the footprints of global climate modes in GRACE-derived TWS over SA, GRACEhydrological signal was deseasonalized (removal of trends and harmonic components) leaving the residual variability hereafter known as dTWS. Based on the multiple linear regression (MLR) technique, the trends and harmonic components of TWS (mean annual and semi annual amplitudes) were compartmentalised from the GRACE time series $\mathbf{Y}_{T W S}$ through parameterizations as (e.g., 52),

$\mathbf{Y}(l, k, t)=\beta_{0}+\beta_{1} t+\beta_{2} \sin (2 \pi t)+\beta_{3} \cos (2 \pi t)+\beta_{4} \sin (4 \pi t)+\beta_{5} \cos (4 \pi t)+\beta_{6} E\left(t+\varphi_{E}\right)+\varepsilon(t)$,

where $(l, k)$ are the grid locations, $t$ is the time in years, $\beta_{0}$ is the constant offset, $\beta_{1}$ is the linear trend, $\beta_{2}$ and $\beta_{3}$ account for the annual signal while $\beta_{4}$ and $\beta_{5}$ represent the semiannual signal. The variable $\beta_{6}$ is the amplitude of TWS changes related to climate indices describing large scale ocean-atmosphere phenomenon (e.g., ENSO, PDO). E is the normalized time series (i.e., after removing long term mean) of each climate mode, $\varphi_{E}$ is the phase lag between the time series of TWS and each climate index, while $\varepsilon(t)$ is the random error term. The amplitudes of TWS (i.e., mean annual and semi annual) over the region are formulated as

$$
\text { Annual Amplitude }=\left[\left(\beta_{2}\right)^{2}+\left(\beta_{3}\right)^{2}\right]^{1 / 2} \text {, Semi Annual Amplitude }=\left[\left(\beta_{4}\right)^{2}+\left(\beta_{5}\right)^{2}\right]^{1 / 2} .
$$

Removing these harmonic components (Eqn 2) and the linear rates in Eqn. 1 leaves the residual component, which is here hypothesized as comprising predominantly slow dynamic climate processes (e.g., over the Pacific, Atlantic, and Caribbean) and other regional forcings. Some of the inherent residual variations however, could also include low frequency noise. The local least-squares polynomial approximation-based filter of Savitzky and Golay (64) was therefore applied to smoothen out such effects from both variables (TWS and climate modes). The deseasonalized $\left(\mathbf{X}_{d T W S}\right)$ signal is characterised as

$$
\mathbf{X}_{d T W S}=\mathbf{Y}-\left[\beta_{1} t+\beta_{2} \sin (2 \pi t)+\beta_{3} \cos (2 \pi t)+\beta_{4} \sin (4 \pi t)+\beta_{5} \cos (4 \pi t)\right]
$$




\subsubsection{Multivariate analyses of terrestrial water storage in relation to climate modes}

The independent component analysis-based cumulant scheme was used to statistically decompose the time series of the data matrix $\mathbf{X}_{d T W S}$ into spatio-temporally independent patterns (e.g., 50, 52, 86). Prior to this, $X_{d T W S}$ was regularized through orthogonalization (i.e., prefiltering) using the principal component analysis (PCA, 47, 31). The interest in identifying periodic signals embedded in multi-resolution climate data is increasing and has resulted in several applications of PCA in the regionalization of climate patterns and in the analysis of geophysical time series around the globe (see, e.g., 49, 1, 29, 44). In addition to its simplicity and being the most widely used statistical data analysis tool in climate science (81), the choice of this technique in this study is because of its unique capability to separate both inter-annual signals, and long-term periodic variations (e.g., 47, 59). So, the statistically significant orthogonal modes of variability from the PCA technique were selected through a scree plot analysis (43). To ensure that only significant orthogonal modes of $X_{d T W S}$ were further analysed, the Bartlett's test statistics (e.g., 69) was also used to examine the number of modes necessary to explain the non-random variations in $X_{d T W S}$ at $95 \%$ confidence level before the implementation of the cumulant scheme, the independent component analysis (ICA). Fundamentally, as indicated in Eqn 4, the scheme decomposes a typical data matrix $\mathbf{Z}_{P}(t)$, into a mixing matrix $B$ and a number of statistically independent source signals $s_{j}(t)$ as,

$$
\mathbf{Z}_{P}(t)=\sum B_{i j} s_{j}(t), \quad(i=1, \ldots, n, \quad j=1, \ldots, m)
$$

where $t$ is the time index, $i$ and $j$ are the rows and columns respectively. Computational details and numerical steps for its implementation and algorithm development have been documented in the earlier works of Cardoso (8), Cardoso and Souloumiac (10), and Common (11), Cardoso (9). GRACE-hydrological signal over SA is considerably strong and dominated by strong annual components that make residual variabilities induced by climate teleconnections and large anomalies of the surrounding oceans difficult to identify. So, the ICA decomposition approach enhances the detection of this kind of less dominant (i.e., obscured) signals and enables their localisation (e.g., 52), making it possible to relate their temporal evolutions concurrently with those of climate modes. After the cumulant decomposition of $\mathbf{X}_{d T W S}$, the evolving independent modes (i.e.., dTWS-1, dTWS-2..., dTWS-n, representing localized hydrological signal in the region) of variability were compared with the normalised time series of each climate modes (Fig. 2). To recover the amplitudes of estimated climate induced TWS for each region, the evolving temporal pattern is jointly interpreted with the corresponding 
spatial pattern.

\subsubsection{Quantifying the contributions of climate modes to changes in terrestrial water storage} The contribution of each of the climate modes (i.e., ENSO, PDO, Nino 3.4, Nino 4, NTA, ETA, STA, and Caribbean) on the amplitudes of TWS was estimated using a least square fit on each grid location of $\mathbf{X}_{d T W S}$ in Eqn. 3 following previous approaches $(52,58)$

$$
\mathbf{X}_{\text {Climate mode }}(x, y)=a(x, y)+b(x, y) * \text { climate mode }+c(x, y) * i m a g(H(\text { climate mode })),
$$

where coefficients $b$ and $c$ are used to estimate the climate induced variations in TWS $\mathbf{X}_{c l i m a t e}$ mode $(x, y)$ at grid locations $(x, y)$, while the imaginary part of the Hilbert transform $(H)$ of the climate index represents the lag between TWS anomalies and climate modes. The pioneering work of Phillips et al. (58) clearly highlighted the importance of Hilbert transformation as a simple tool in Fourier analysis that move the sinusoidal Fourier components of the signal (e.g., ENSO, PDO, etc.) by 90 degrees. In the prediction of ENSO episodes from the SOI observations, Salisbury and Wimbush (62) found the Hilbert transform quite useful in the analysis of nonlinear and non-stationary time series. After the estimation of coefficients $b$ and $c$ in Eqn. 5 above, the amplitude of climate-induced dTWS was computed as

$$
A=\left[b^{2}+c^{2}\right]^{1 / 2}
$$

where $A$, is the estimated magnitude of climate mode on continental TWS (i.e., the estimated contribution of each of the climate modes to observed variations in TWS).

\subsection{Precipitation over South America: amplitudes and covariability with climate modes}

Although the focus of this study is on identifying climate modes in GRACE-derived TWS, deseasonalized rainfall was also decomposed using the ICA technique. The leading temporal evolution of TRMM-based precipitation was thereafter compared with key climate modes, such as the PDO and ENSO-related teleconnections. The covariability of these climate oscillations with the leading independent pattern of rainfall is aimed at exploring further perspectives on the impacts of teleconnection-induced rainfall on TWS. Furthermore, the mean annual and semi annual amplitudes of precipitation over South America were also retrieved by using Eqn 2. This was necessary to initiate a further understanding of the roles of key multi-scale global climate teleconnections on the spatio-temporal patterns of rainfall on hydrological hot spots (regions with significant impact of climate modes on TWS). 

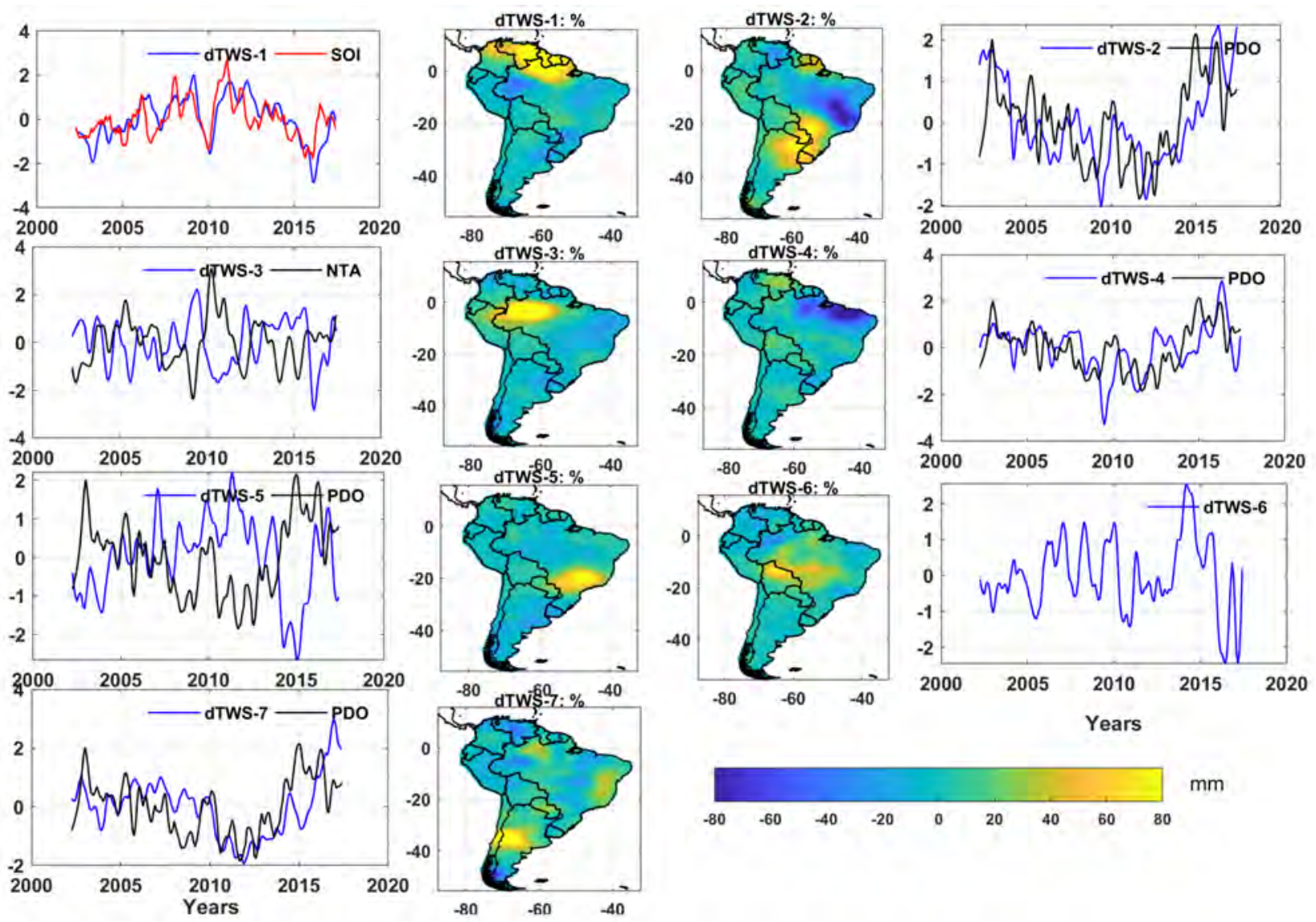

Figure 2: Cumulant decomposition of TWS over South America after removing all harmonic components (mean annual and semi annual amplitudes) and linear rates using the MLR. The spatial patterns (columns 2 and 3 ) are scaled using the standard deviations of the computed independent components (columns 1 and 4). The relationship between the normalized time series of climate modes (ENSO, NTA and PDO) and the independent temporal series are also shown.

\section{Results}

\subsection{Impacts of global climate modes on GRACE-hydrological signals}

The novel approach in this study integrates parameter estimation method with the ICA technique sequentially. Firstly, the harmonic components and trends in GRACE-hydrological signals were removed through a parameterisation process based on MLR (multiple linear regression) formulation (Eqns. 1-3). This is essential as these quantities (harmonic components and trends) dominate TWS variability and would make tracking the footprints of climate modes rather difficult $(52,58)$. Secondly, the contributions and impacts of teleconnections and SST products on continental land water storage were assessed through a fourth order cumulant decomposition of the output from the MLR scheme (i.e., significant modes of deseasonalised TWS, i.e., dTWS) into spatio-temporal independent patterns (Fig. 2). The strongest influ- 
Table 1: Correlation coefficients showing the relationship of climate teleconnections (PDO, ENSO, SOI) and SST products (Nino 3.4, Nino 4, Nino 3.0, Nino 1+2, North Tropical Atlantic-NTA, East Tropical AtlanticETA, South Tropical Atlantic-STA, and Caribbean) with localised TWS (i.e., dTWS) over South America. This localised TWS is the independent component (IC) associated with spatial patterns. Correlation coefficients in bold are significant at $\alpha=0.05$

\begin{tabular}{cccccccccccc}
\hline IC (dTWS $)$ & Nino3.4 & Nino4 & PDO & SOI & NTA & ETA & STA & Caribbean & ENSO & Nino $1+2$ & Nino 3.0 \\
\hline 1 & $\mathbf{- 0 . 6 8}$ & $\mathbf{- 0 . 7 2}$ & $\mathbf{- 0 . 6 9}$ & $\mathbf{0 . 6 4}$ & -0.15 & -0.13 & -0.18 & $\mathbf{- 0 . 6 7}$ & $\mathbf{- 0 . 7 1}$ & $\mathbf{- 0 . 3 0}$ & $\mathbf{- 0 . 5 3}$ \\
2 & $\mathbf{0 . 3 4}$ & $\mathbf{0 . 3 5}$ & $\mathbf{0 . 5 4}$ & $\mathbf{- 0 . 2 8}$ & 0.02 & $\mathbf{0 . 2 6}$ & $\mathbf{0 . 3 3}$ & $\mathbf{0 . 4 4}$ & $\mathbf{0 . 3 6}$ & $\mathbf{0 . 2 5}$ & $\mathbf{0 . 2 8}$ \\
3 & 0.12 & 0.09 & 0.06 & -0.14 & $\mathbf{- 0 . 5 1}$ & -0.23 & -0.09 & $\mathbf{- 0 . 2 4}$ & 0.16 & $\mathbf{0 . 2 6}$ & 0.20 \\
4 & 0.21 & 0.25 & $\mathbf{0 . 4 1}$ & $\mathbf{- 0 . 2 5}$ & 0.06 & 0.02 & -0.06 & $\mathbf{0 . 4 1}$ & $\mathbf{0 . 3 2}$ & -0.00 & 0.09 \\
5 & $\mathbf{- 0 . 3 0}$ & $\mathbf{- 0 . 3 3}$ & $\mathbf{- 0 . 5 8}$ & $\mathbf{0 . 3 0}$ & $\mathbf{0 . 3 0}$ & 0.05 & 0.07 & -0.13 & $\mathbf{- 0 . 3 1}$ & -0.22 & $\mathbf{- 0 . 2 6}$ \\
6 & 0.13 & 0.12 & 0.02 & -0.18 & -0.19 & -0.07 & -0.05 & -0.19 & 0.15 & 0.15 & 0.17 \\
7 & $\mathbf{0 . 2 5}$ & $\mathbf{0 . 2 7}$ & $\mathbf{0 . 4 6}$ & $\mathbf{- 0 . 3 3}$ & -0.01 & 0.13 & 0.09 & $\mathbf{0 . 3 6}$ & $\mathbf{0 . 3 2}$ & $\mathbf{0 . 2 8}$ & 0.23 \\
\hline
\end{tabular}

ence of these climate modes are considerably notable in tropical SA (South America), which encompasses the Amazon and northern catchments of the continent (dTWS-1, Fig. 2). Based on Pearson's correlation $(r)$, ENSO, PDO, SOI, SST anomalies of the Caribbean and Pacific oceans (Nino 4 and Nino 3.4), which corresponds to the ENSO region show the highest association $(r=-0.68,-0.72,-0.69,-0.67$, and -0.71 for Nino 3.4, Nino 4, PDO, Caribbean, and ENSO, respectively) with the temporal evolutions of TWS over Amazon and northern catchments (Figs. 3a-f and Table 1). Moreover, independent patterns of TWS variations over SA in general, are largely associated with the PDO signal (dTWS-1, dTWS-3 to dTWS-5, and dTWS-7, Fig. 2 and Table 1) except for the central Amazon basin where NTA also show a modest association (dTWS-2, Fig. 2) with a correlation $(r)$ of -0.51 . SST products from relatively closer oceans, Ninos $1+2$ and 3.0 show significant relationship with the region tropical SA ( $r=-0.30$ and -0.53 , respectively). Caribbean SST also show moderate relationship with TWS evolutions in regions dTWS-2 and dTWS-4 of Fig. 2 and indicates $r=0.44$ and $r=0.41$, respectively. The relationships of these climate modes with the temporal patterns of TWS have been summarised in Table 1 and highlights the significant footprint of global climate in observed TWS over tropical SA.

In terms of numerical results, there is a methodological agreement in the two statistical frameworks used to assess the influence of these climate modes on land water storage dynamics over SA. From the localised spatial and temporal patterns obtained from cumulant decomposition (dTWS-1, Fig. 2), relatively higher amplitude of TWS is observed in the northern-Amazon section (i.e., Orinoco and Amazon basins, Fig. 1). As estimated from the MLR technique, the strongest amplitude of TWS induced by these climate modes were observed in this same region 

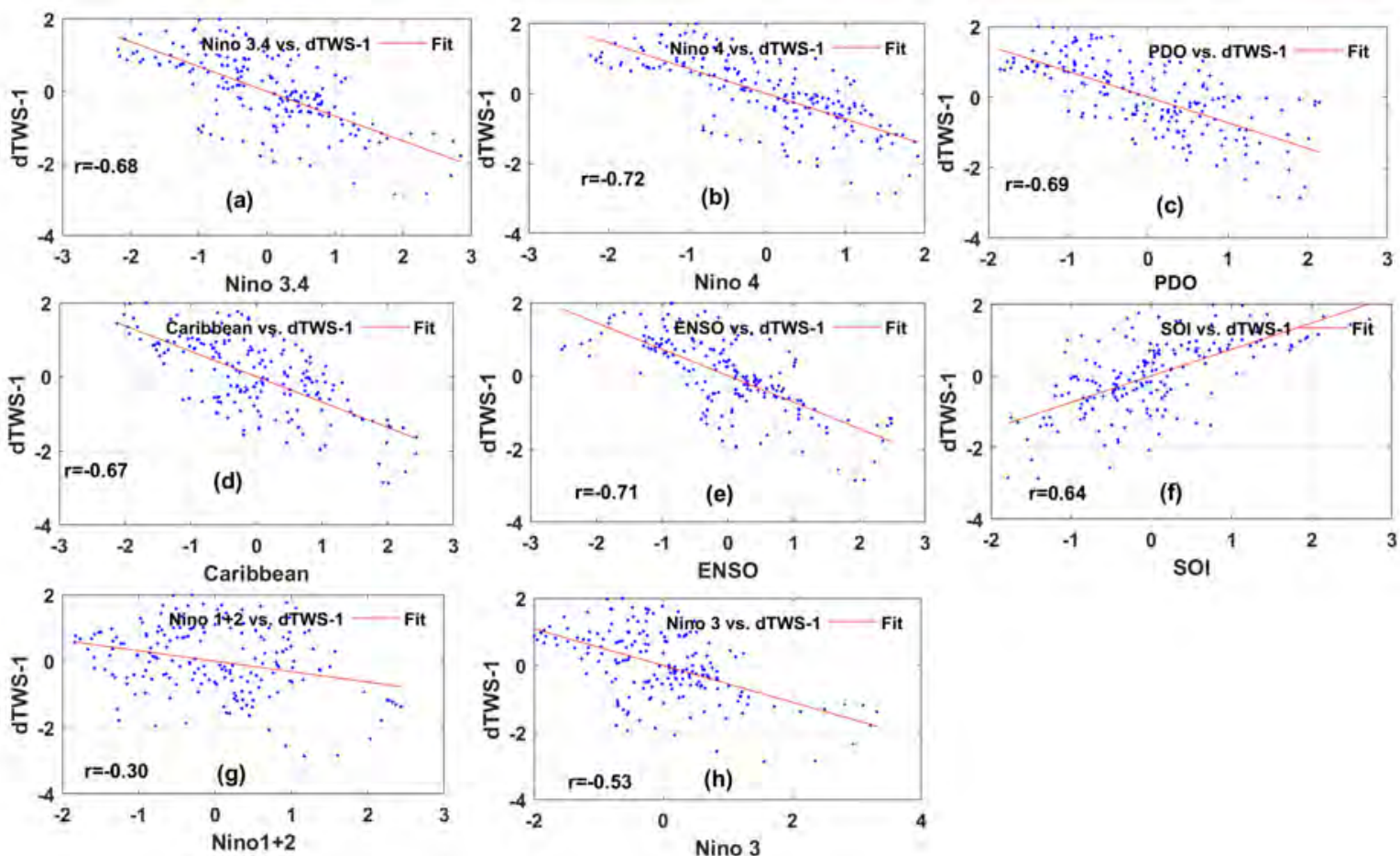

Figure 3: Influence of PDO and SST products (Ninos 1+2, 3.0, 3.4, 4.0, and Caribbean) on localised TWS in the north east and upper Amazon basin regions (dTWS-1, Fig. 2) based on linear regression. (a) dTWS-1 vs Nino 3.4, (b) dTWS-1 vs Nino 4, (c) dTWS-1 vs PDO, (d) dTWS-1 vs Caribbean, (e) dTWS-1 vs ENSO, (f) dTWS-1 vs SOI, (g) dTWS-1 vs Nino 1+2, and (h) dTWS-1 vs Nino 3.

(Figs. 4a-i), consistent with the cumulant decomposition technique. In the Amazon/northern section, the influence of ENSO, SOI, Nino 4, and Nino 3.4 results in considerable magnitudes of more than $100 \mathrm{~mm}$ to the amplitudes of TWS (Figs. 4a, c-d, and g). The contribution of these climate modes to TWS in this location coincides with their strong temporal relationships with TWS in the same region (Figs. 3a-f). As Nino 4 and Nino 3.4 are signals from the ENSO region (i.e., Central/East Central Pacific), TWS variations in the Amazon and northern catchments of the continent are more driven by the ENSO phenomenon. Moreover, the Caribbean SST show considerable association with relatively higher amplitudes of TWS in the south-east section of the continent (Fig. 4e). Bearing in mind the low association of ETA and STA with TWS (Table 1) in all hydrological regions as localised in Fig. 2, climate induced amplitudes of TWS were only estimated for ENSO, PDO, SOI, NTA, Ninos 1+2, 3.0, 3.4, 4.0, and Caribbean SST (Figs. 4a-i).

Taking advantage of a 15-year GRACE data, this study confirms that El Niño induced water deficits (positive phase) and increased TWS (negative phase) (e.g., 14) caused by La Niñas in the Amazon region are more likely to be the direct influence of SST anomalies in 

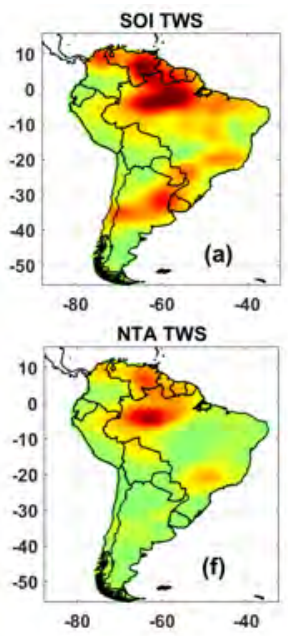

the surrounding oceans. Although the SOI shows positive correlations with dTWS-1 (Fig. 2) as opposed to other Ninos $(1+2,3,3.4$, and 4) and ENSO (Figs. 3a-b, e, and g-h), as a reminder, they are all ENSO-related teleconnections and result in higher (lower) amplitudes during the La Niñas (El Niños) episodes as highlighted earlier. This is because sustained negative (positive) values of SOI below a certain threshold indicate El Niño (La Niña) events. Further, the grid-base relationships between these climate modes and TWS indicate that land water storage in much of tropical SA are impacted by the Caribbean SST, SOI, PDO, eastern-Pacific and central-Pacific-related ENSOs (Figs. 5a-k). Whereas STA and ETA show very minor and limited influence on TWS (Figs. 5g-h), PDO, ENSO, and Caribbean SST have extensive significant influence over the continent, showing relatively higher correlations ranging from about 0.7 to 1 (Figs. 5b, e, i,). However, the spatial correlations between Ninos $1+2$ and 3 with TWS are also high but location-specific and in addition suggest the influence of SST from relatively closer oceans on TWS (Figs. 5j and k). Despite the agreements between TWS and climate modes in $\mathrm{SA}$, the contributions and influence of these climate teleconnections to TWS in some regions are statistically insignificant while much of the continent show significant contributions (Supporting information, S1).

\subsection{Multi-decadal variations in TWS}
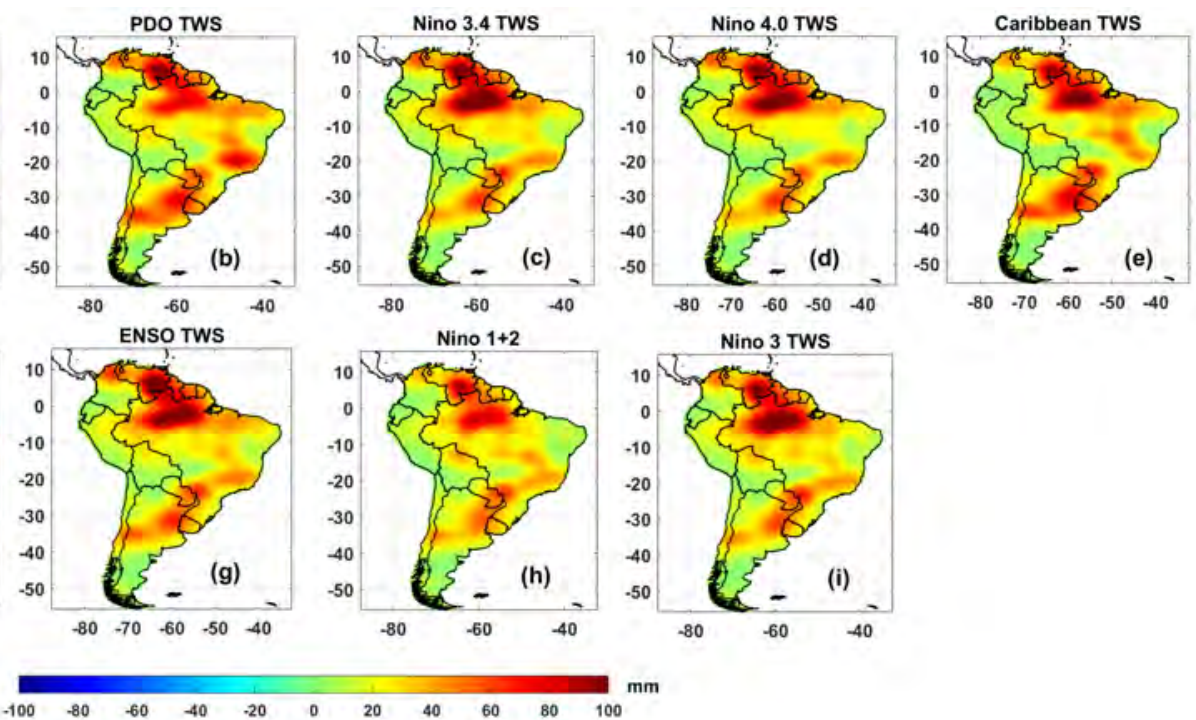

Figure 4: Quantifying the contributions of climate modes and SST products on TWS over South America (a) SOI, and (b) PDO, (c-d) Ninos 3.4 and 4, (e) NTA, (f) Caribbean, (g) ENSO, and (h-i) Nino 1+2 and Nino 3, respectively. These estimates are climate induced amplitudes of TWS obtained using a least square fit on each grid location of dTWS (i.e., Eqns 5 and 6)

Apparently, the temporal series of TWS are characterised by inter-annual variations (Fig. 2). 
But multi-decadal variability is also evident in the temporal patterns of TWS in some of the regions (dTWS-1, dTWS-2, dTWS-4, dTWS-5, and dTWS-7, Fig. 2). These regions show a change in phase after 2010, consistent with the PDO time series. For instance, the increasing (2002 - 2009) and decreasing (2010 - 2015) phases of TWS in dTWS-1 coincide with those of SOI (dTWS-1, Fig. 2 and Table 1). From the numerical results, it is obvious the PDO is in opposite phase in regions dTWS-1 and dTWS-5 while maintaining similar phase relationship with regions dTWS-2, dTWS-4, and dTWS-7 (Fig. 2). Generally, PDO shows modest and considerable associations with TWS in these regions (Table 1). In the lower Colorado River basin, PDO appeared to have been strongly correlated with deep soil moisture (28). Moreover, the influence of PDO on hydro-climatic conditions in North America has been reported in previous studies (e.g., 28, 41). The results in this study also highlights the influence of PDO on TWS over SA and could imply that the low-frequency mode of the PDO regulate both the Northern and Southern American climate. As with ENSO, the positive PDO phase is associated with droughts while the negative phase is linked to extreme wet conditions (i.e., depending on the region in Fig. 2). Although the PDO is more correlated with ENSO at inter-annual scales $(38,41)$, its links with TWS in much of SA (Fig. 5b) suggests a reasonable multi-decadal influence in the variability of TWS. This reaffirms the explicit role of ENSO and PDO as important multi-scale process of water availability not just in the southwestern United States (28), but as significant drivers of GRACE-hydrological signal over SA.

\subsection{Precipitation over South America: Amplitudes and impacts of climate teleconnections}

Some teleconnection patterns (ENSO, PDO, Ninos 3.4 and 4, and the Carribean SST anomalies) were also identified in the TRMM-based precipitation over SA (Figs. 6a-b). The river basins in SA whose precipitation patterns are influenced by these teleconnections include, Orinoco, Amazon, Uruguay, Parana, amongst others (Figs. 6a, cf. Fig. 1a). From the independent patterns of rainfall highlighted in Figs. 6a-b, the ENSO-related teleconnections showed the strongest associations $(r=0.71,0.67,0.66,0.67$ for Nino 3.4, Nino 4.0, ENSO, and Nino 3.0 , respectively) with rainfall in these areas. However, Nino $1+2(r=0.48), \operatorname{PDO}(r=0.40)$, and SOI $(r=-0.58)$ were also moderately associated with rainfall in this region (Fig. 6a). Interestingly, the influence of climate modes on the spatial and temporal distribution of TWS in these climatically diverse sub-regions are also obvious (Figs. 4). On the one hand, the areas with considerable amplitudes in annual and semi-annual rainfall tend to show considerable amplitudes in climate-induced TWS while on the other hand, water-deficit and arid climates 


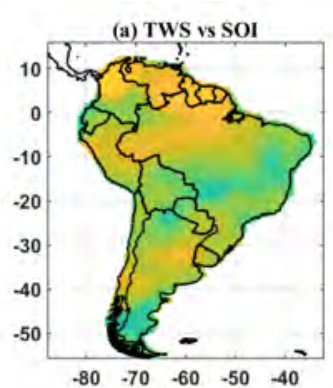

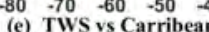

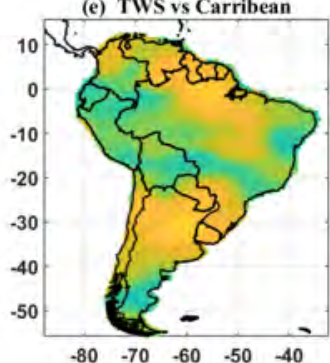

(i) TWS vs ENSO

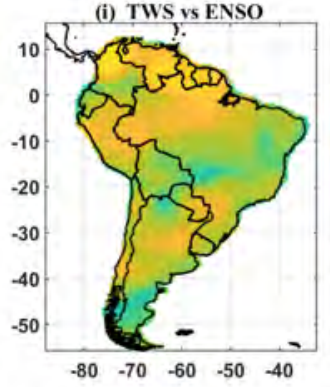

(b) TWS vs PDO

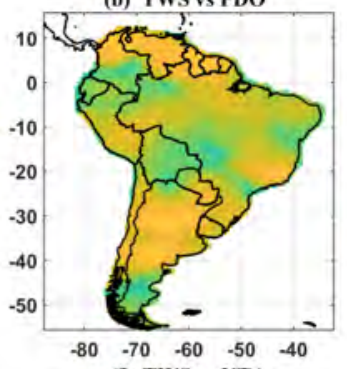

(f) TWS vs NTA

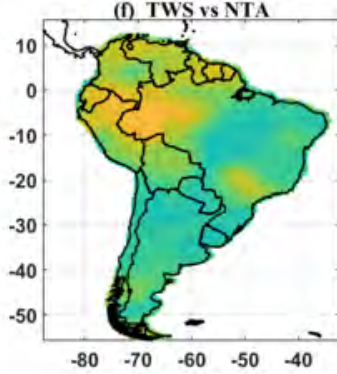

(j) TWS vs Nino $1+2$

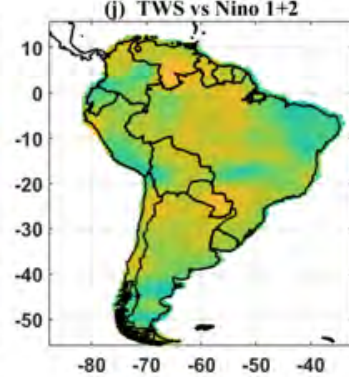

(c) TWS vs Nino 3.4
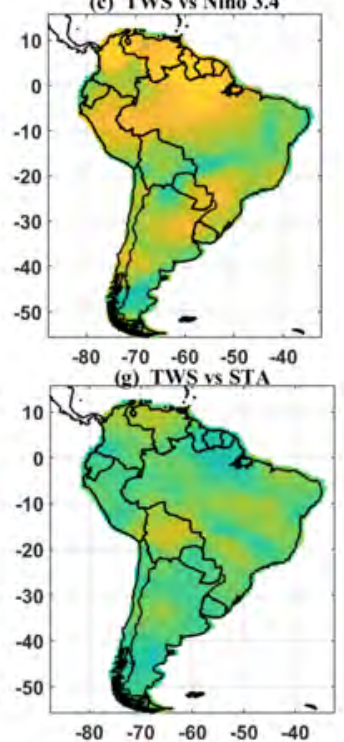

(k) TWS ys Ning 3.0

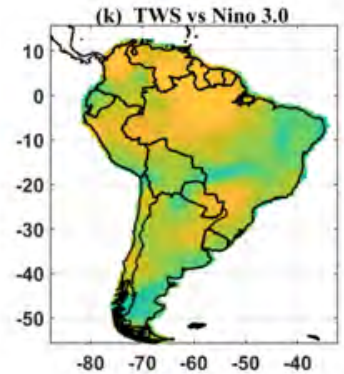

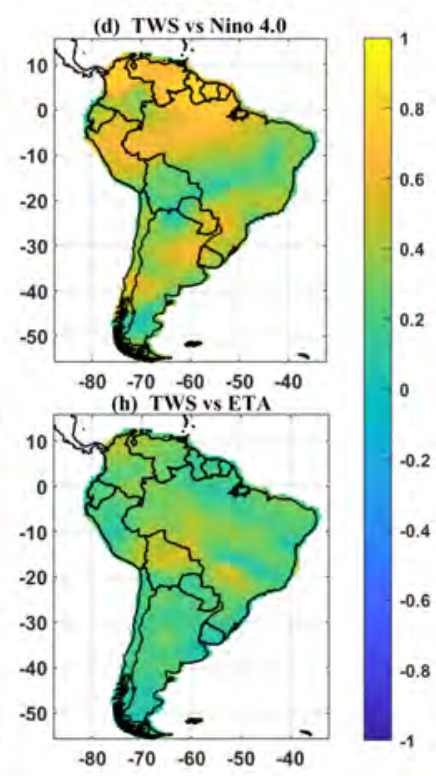

Figure 5: Association between TWS $(2002-2017)$ over South America and all climate oscillations (a-k) examined in this study based on Pearson's correlation coefficients.

that receive relatively lower annual rainfall show modest amplitudes in climate-induced TWS (Figs. 6c-d, 4, and cf. 1a-b). However, TWS in some river basins in the dry tropics of SA where mean annual amplitude in rainfall ranges from about $20 \mathrm{~mm}$ to 100 (Fig. 6c) indicate significant associations with ENSO, PDO, and Carribean SST (Figs. 5b, e, and i).

\section{Discussion}

\subsection{Identifying multi-scale global climate footprints in GRACE-hydrological signals}

Globally, the direct and remote impacts of tropical oceans and quasi periodic signals on rainfall extremes are well known $(35,18,40,82,56)$. This litany of evidence has recently been corroborated further and indicates that SST anomalies of the surrounding oceans and the ENSO phenomenon have large scale influence on hydro-meteorological processes (e.g., 51). Some pioneering studies (e.g., 52, 38, 58, 7, 28) found significant impacts of ENSO and other teleconnections on continental freshwater dynamics. While variations in global soil moisture have been associated with variabilities in ENSO (e.g., 68), new results re-emphasising and 

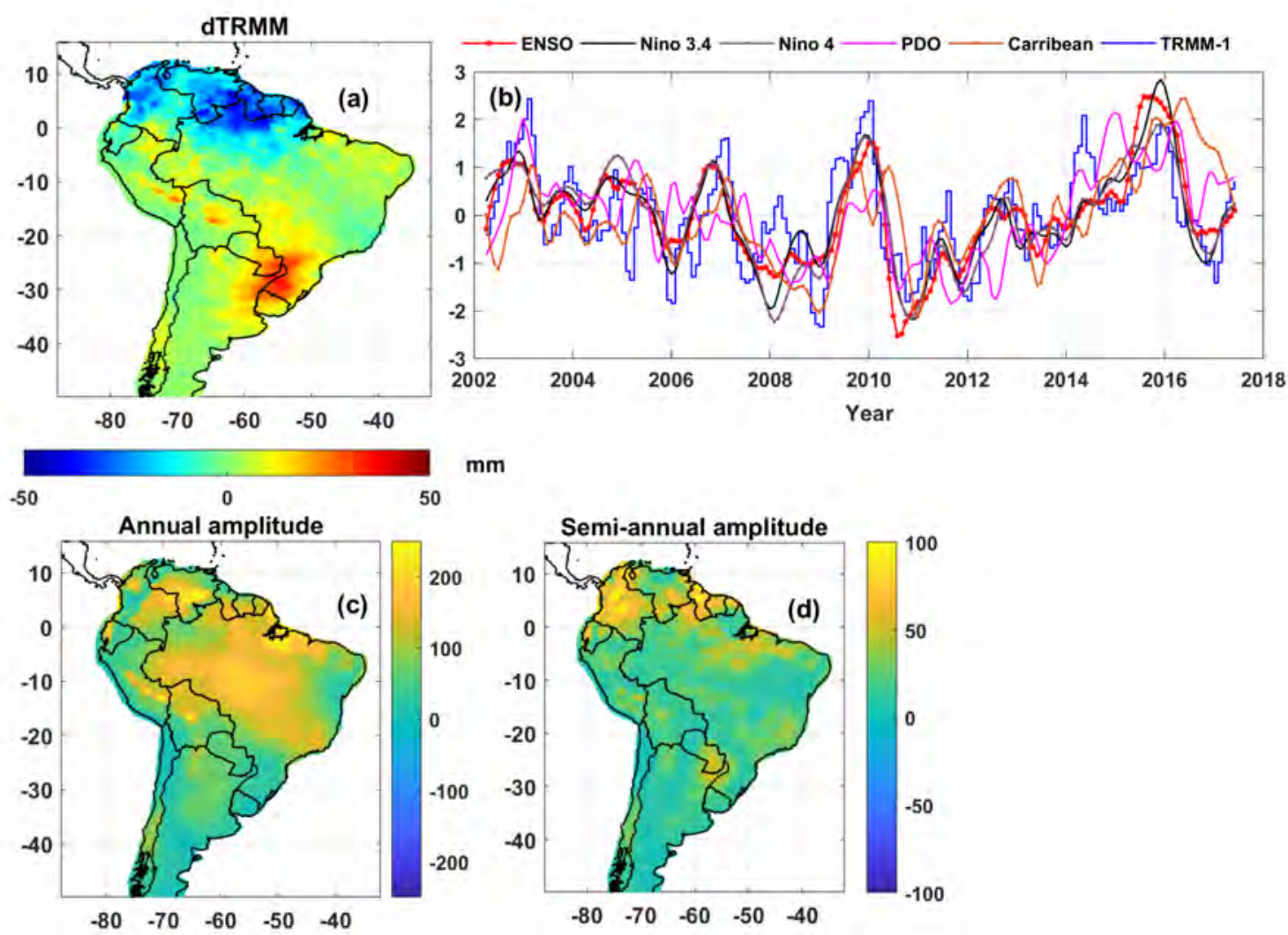

Figure 6: TRMM-based precipitation patterns and role of multi-scale global climate teleconnections. (a) ICA-derived spatial patterns of rainfall, (b) relationship between independent component and climate teleconnections, (c) mean annual amplitude, and (d) mean semi-annual amplitude.

validating the influence of ENSO on variations in hydrological state variables are emerging (e.g., 53, 5, 55). The numerical results presented in this study show that ENSO, PDO, and the Caribbean SST have considerable influence on TWS in the Amazon basin/northern section of SA (dTWS-1, Figs. 2 and 3). The statistical relationships of Ninos 1+2, 3.0, 3.4, and 4.0 with TWS also highlight the influence of SST anomalies in the tropical Pacific and around coastal South America on the continent (Figs. 4-5).

Except for NTA, which shows relatively strong impacts only in the central Amazon basin (Fig. 4f), the influence of ENSO, PDO, Ninos 3.4 and 4.0 and the Caribbean SST on the spatial distributions of TWS spreads to the southern region of the continent of SA (Figs. 4ae and Table 1). These findings align closely with the earlier work of Linage et al. (38) in tropical SA, which of course excludes much of the region we have studied (i.e., below Latitude 18S). The widely reported influence of ENSO on rainfall and TWS patterns in the Amazon basin and environ as summarised by Linage et al. (38) is not only consistent with our findings but affirms our hypothesis that indices of oceanic variability and the nearby oceans regulate 
precipitation, which in turn impacts on continental TWS. Apart from the Pacific (Ninos $1+2$, 3.0, 3.4 and 4) and Atlantic (NTA) SSTs influence on the northeastern and Amazon sections of SA, our innovative approach of combined cumulant and parameter estimation methods has further revealed the significant contributions and influence of the Caribbean SST on the spatiotemporal distributions of TWS in the region (Figs. 3d and 4e). Hence, incorporating these large scale climatic drivers in a predictive scheme could improve the modelling of freshwater availability on a continental scale.

Given the PDO-TWS relationship, there is also a considerable evidence to suggest multidecadal variability in the observed time series of TWS over SA. This observed relationship could have some implications on modelling frameworks and water management. For example, the increased surface water use for hydropower and agriculture in Brazil, which is the main beneficiary of surface water from the Amazon/northern region of SA will therefore require an improved monitoring and governance scheme to help address water issues related to availability and the impacts of extreme hydro-climatic conditions (droughts). Given the irregularity in the periodicity of the PDO mode, which makes it difficult to predict its evolutions (e.g., 28), understanding the effects of PDO on the hydrological conditions on surface water hydrology in SA is a pathway to optimising freshwater forecast. The impacts of the positive and negative PDO phases on the climate and environment have significant implications on fisheries and evolution of water resources (e.g., 41). For instance, in the Colorado River basin, Hurkmans et al. (28) found that during the negative PDO phase, mean absolute anomalies of shallow soil moisture, snow, and discharge were slightly lower unlike the positive PDO phase. All over the western and central North America, negative PDO phase coincided with severe and prolonged dry conditions $(28,41)$. Although the causes of phase shifts in the PDO is unknown as it is quite a complex and somewhat unpredictable (e.g., 54, 77, 41, 28), the knowledge about the impacts of the two PDO phases on water resources and the ability to predict its phase shifts could be a useful benchmark in freshwater modelling. If the shifts in PDO phases are forced by strong El-Niño and La-Niña patterns as highlighted in past studies (e.g., 77, 41), new opportunities that leverage on the unique contrast in ENSO 's behaviour during these PDO phases could be useful to optimizing global climate predictive frameworks.

Furthermore, some new and emerging studies are reaffirming the critical roles of climate teleconnection patterns, low-frequency variability in the surrounding oceans, and several other physical mechanisms on the evolutionary patterns of rainfall across the globe. For instance, besides the well known influence of topography on East African rainfall (e.g., 57), the impacts 
of ENSO, Indian Ocean Dipole (IOD), and low-frequency variability in the Pacific Ocean have been identified while the convergence of anomalous northerly and southerly winds in the lower troposphere were found to have intensified summer rainfall over central East China (see, e.g, 6, 78, 80). Similarly, rainfall in tropical SA are also influenced by these suite of global teleconnections, especially the ENSO-related climate oscillations (Figs. 6a-b). Indeed, the various mechanisms governing meteorological processes (e.g., monsoon circulations and other large scale atmospheric patterns) globally are expected to have different degrees of direct or remote contributions to TWS at local and continental scales. We found this to be true for tropical SA where these teleconnections were identified in TRMM-based precipitation (Figs. 6ab), consistent with areas that showed considerable TWS-climate teleconnection relationship (Figs. 5a-k). Given the scientific basis that the impacts of teleconnections on rainfall will be different from TWS, which act as a buffer to rainfall (e.g., 47), atmospheric circulations, oceanic processes, and climate oscillations, which induce large precipitation anomalies will therefore result in the acceleration and intensification of the water cycle. For example, several components of the water cycle (e.g., precipitation, river discharge) and hydrological state (e.g., soil moisture) variables are known to be influenced by ENSO and several other global climate teleconnections e.g., PDO, IOD, etc (e.g., 4, 52, 28, 13, 68).

\subsection{Non-climatic influence on terrestrial hydrology}

As opposed to other hydrological regions where seasonality and inter-annual variations in lakes, rivers, and natural systems do not have significant contributions to observed changes in the GRACE water column $(23,34)$, TWS over much of tropical SA (e.g., Amazon basin) is considerably driven mostly by its surface waters and sub-surface storage (e.g., 34). However, while water availability is considerable higher in the extremely wet tropical regions of SA such as the Amazon basin (Fig. 1a), the typically dry regions of the continent (e.g., north-east Brazil) depend on the water resources of these wet regions. This has resulted in a plethora of water resources development for agriculture, hydro-power generation, industrial and domestic applications. The 2017 report on water use in Brazil (see, 2) has this documented and indicates that irrigation, urban supply, power plants, and industrial applications accounted for about $46 \%, 23 \%, 10 \%$, and $9 \%$, respectively, of the total water withdrawals. While the report further predicts a rise of $30 \%$ in water withdrawals in Brazil by 2030, the proliferation of dams and heavy reliance on human-water infrastructures for the provision of freshwater and other ecosystem services could have significant impacts on land water storage dynamics. 
Isolating non-climatic hydrological time series of surface water storage caused by human water management strategies is therefore a key methodological development that will be required to optimise the assessment of climate teleconnections to changes in surface hydrology.

The strength of association between TWS and observed climate modes in some hydrological regions of SA may suggest the important role of non-climatic drivers, especially those caused by human activities and other environmental factors (e.g., subsidence caused by earthquakes). Poor correlations between TWS and climate patterns are rather obvious for most regions of North-east Brazil, and some areas of Pantanal and towards the south of Chobut (Figs. 5a-k, cf. Fig. 1). Further, Chile is one of the most complex hydrological regions in SA with higher vulnerability to vertical deformations, seismicity, and earthquakes. (see, e.g., 46, 30). With increased frequency in earthquakes, deformations, and other forms of natural disturbances (e.g., 20, 61, 30, 75, 39), the terrestrial hydrology of regions like Chile and the neighbouring Argentina is expected to also be characterised by non-climatic signals. Put together, these nonclimatic factors, be it anthropogenic influence or natural factors, induce considerable changes in terrestrial hydrology.

Furthermore, trends in observed TWS in tropical SA were attributed to multiple factors, including human-induced increase in land surface temperatures, decadal variations in the North Pacific climate, and land use/cover changes (38). The recent diagnostics of various drivers of global freshwater systems suggest natural variability and climate change are the leading drivers of TWS over SA (60). This is evident in some tropical wet river basins where catchments with relatively higher rainfall amount (Fig. 1a) tend to experience stronger amplitudes and changes in TWS (Fig. 1b). Indeed, ENSO drives changes in large-scale atmospheric circulation patterns that regulate inter-annual variations in meteorological processes, leading to floods, extreme droughts, and strong monsoon changes (e.g., 51, 25). In South America, extreme droughts and water deficit conditions have been attributed to the impacts of ENSO (e.g., 16, 70) while significant relationship between ENSO and observed TWS in tropical South America has been reported (e.g., 55, 58). Building on the pioneering work of Linage et al. (38), which identified climate teleconnections between TWS and SST anomalies from the surrounding oceans, this study emphasizes the continued improvements of understanding related to regional climate processes that provide constraints on water availability in South America. Given that some regions with relatively low annual rainfall also show moderate rise in TWS, hydrological processes and the dynamics of land water storage however, could be complicated in SA because of the interplay between geodetic perturbations and climate variability. Gener- 
ally, depending on the dynamic processes and geodetic characteristics of a region, geophysical signals as observed by GRACE are expected to be a mixed of climate, natural, and those caused by environmental factors. Hence, be it at regional or continental scale, further investigation is essential to unravelling the composite influence of human and environmental factors on GRACE-hydrological signals.

\section{Conclusion}

Global climate change will fundamentally continue to amplify water scarcity through increased variability. Therefore, predicting freshwater systems at regional or continental scales require an assessment of the interplay between large multi-scale climatic systems and hydrological processes. To this end, the novel integration of independent component analysis with parameter estimation techniques was employed to assess the complex interaction of key oceanic hotspots (Pacific, Atlantic and Caribbean) with continental freshwater dynamics over South America (SA). Whereas such assessment has become necessary for SA, which is one of the world's water tower, accounting for nearly one fifth of global continental freshwater discharge, taking advantage of a 15-year GRACE data to demonstrate the efficiency of our proposed statistical framework is critical for some reasons. Firstly, this will improve contemporary understanding of hydrological processes and drivers of land water storage on a regional or continental scale. Secondly, in the light of limited ground observations for hydrological applications, it further articulates the potential of time-variable gravity observations as an efficient tool to assess the role of multi-scale climate oscillations on land water storage. As a proof of concept, the methodological framework in this study was also useful to identifying the regions in SA whose precipitation are also driven by global climate teleconnections.

The Pacific (Ninos 1+2, 3.0, 3.4 and 4.0), Atlantic (North Tropical Atlantic), and Caribbean SSTs anomalies influence the spatio-temporal distributions of TWS over SA with the northeastern and Amazon sections receiving the most impact. The associations of other Atlantic SST (East Tropical Atlantic and South Tropical Atlantic) anomalies with TWS are also significant $(\alpha=0.05)$ but contributions are small and catchment-specific (around Pantanal and the extreme south of the Amazon basin) compared to the Pacific SST. Overall, ENSO shows the strongest association with continental TWS dynamics. There is also a considerable amount of evidence to speculate that the observed time series of TWS over different hydrological regions of SA are driven by multi-decadal global climate patterns (i.e., PDO). As ENSO, PDO, Ninos 3.4 and 4, and the Carribean SST signals were also identified in satellite precipitation over 
tropical SA, these teleconnection patterns are expected to provide significant controls on the evolutions of extreme hydro-climatic patterns in the region. Indeed, these patterns (ENSO, PDO, Ninos 3.4 and 4, and the Carribean SST), including Nino 3.0 and SOI were the most associated with TWS in much of SA.

Given that TWS in most tropical systems are dominated by strong inter-annual variability caused by changes in precipitation patterns, the perceived roles of human induced climate change are also expected to result in increased freshwater variability. While this is evident in some tropically-wet river basins of SA where catchments with relatively higher rainfall amount tend to experience stronger amplitudes and changes in TWS, hydrological processes and the dynamics of land water storage could be a rather complex phenomenon in SA. This is because of the interplay between the role of geodetic perturbations and the influence of global climate teleconnections on TWS, especially the possibility of the former in inducing large changes in GRACE-derived TWS in SA. Whereas this study offers a rather systematic blue print to help identify the foot prints of global climate patterns, further investigation is essential to unravelling the composite influence of human and environmental factors on GRACE-hydrological signals over SA. Finally, while being cautious about the interpretations of some results on the observed relationships of climate modes with terrestrial water storage, further understanding related to regional climate processes that provide constraints on water availability in South America is advocated. 


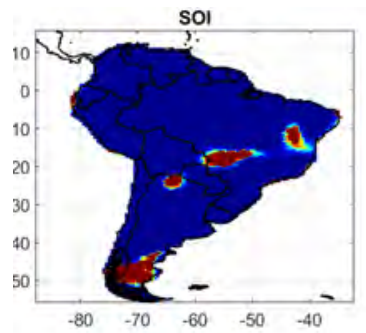

Carribean
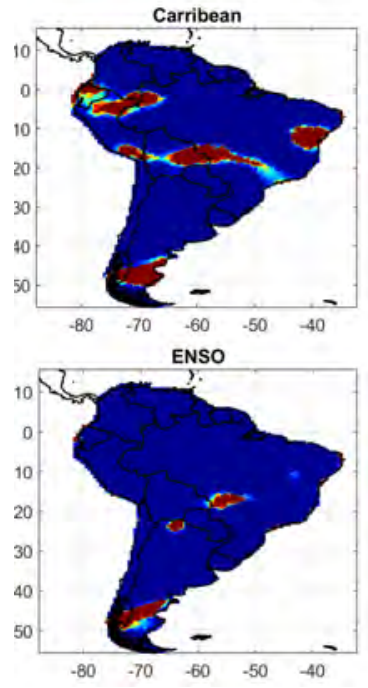
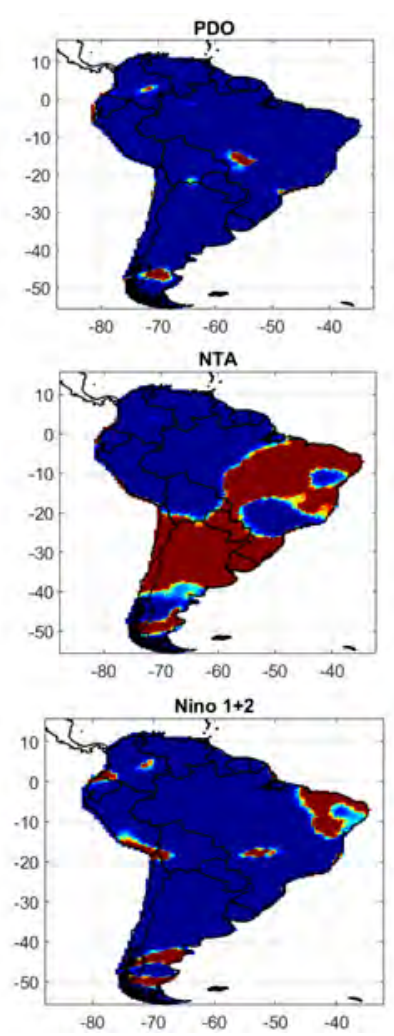
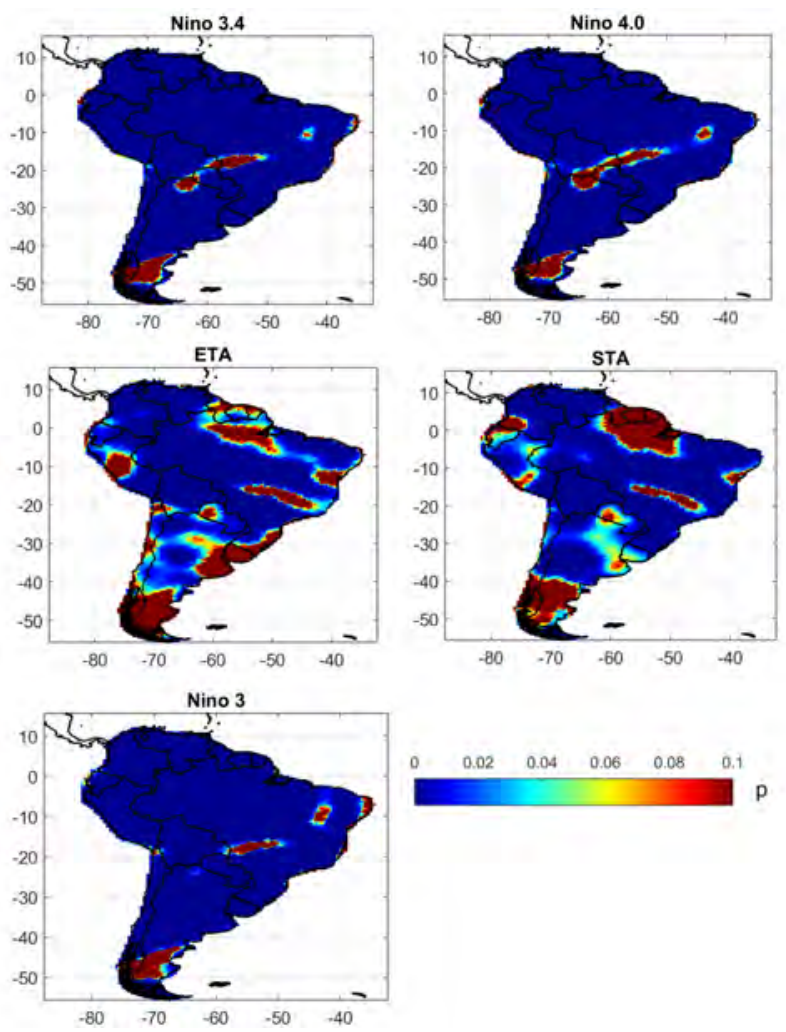

Figure 7: Statistical significance $(\alpha=0.05)$ of estimated contributions and relationship of climate modes with amplitudes of GRACE-derived TWS (2002 - 2017) over South America.

\section{Acknowledgments}

The authors are grateful to the Center for Space Research at The University of Texas for providing the level 3 GRACE data used in this study. 


\section{References}

[1] Agutu, N., Awange, J., Zerihun, A., Ndehedehe, C., Kuhn, M., and Fukuda, Y. (2017). Assessing multi-satellite remote sensing, reanalysis, and land surface models' products in characterizing agricultural drought in East Africa. Remote Sensing of Environment, 194(0):287-302. doi:10.1016/j.rse.2017.03.041.

[2] ANA (2017). Brazilian water resources report 2017. National Water Agenccy.

[3] Andam-Akorful, S., Ferreira, V., Ndehedehe, C. E., and Quaye-Ballard, J. (2017). An investigation into the freshwater variability in West Africa during 1979-2010. International Journal of Climatology, 37(S1):333-349. doi:10.1002/joc.5006.

[4] Andam-Akorful, S. A., Ferreira, V. G., Awange, J. L., Forootan, E., and He, X. F. (2015). Multi-model and multi-sensor estimations of evapotranspiration over the Volta Basin, West Africa. International Journal of Climatology, 35(10):3132 -3145. doi:10.1002/joc.4198.

[5] Anyah, R., Forootan, E., Awange, J., and Khaki, M. (2018). Understanding linkages between global climate indices and terrestrial water storage changes over africa using GRACE products. Science of The Total Environment, 635:1405 - 1416. doi:10.1016/j.scitotenv.2018.04.159.

[6] Bahaga, T. K., Fink, A. H., and Knippertz, P. (2019). Revisiting interannual to decadal teleconnections influencing seasonal rainfall in the Greater Horn of Africa during the 20th century. International Journal of Climatology.

[7] Boening, C., Willis, J. K., Landerer, F. W., Nerem, R. S., and Fasullo, J. (2012). The 2011 La Niña: So strong, the oceans fell. Geophysical Research Letters, 39(19):L19602. doi:10.1029/2012GL053055.

[8] Cardoso, J.-F. (1991). Super-symmetric decomposition of the fourth-order cumulant tensor, blind identification of more sources than sensors. Retrieved from:http://perso.telecomparistech.fr/ cardoso/Papers.PDF/icassp91.pdf. Accessed 15 January 2016.

[9] Cardoso, J. F. (1999). High-Order contrasts for Independent Component Analysis. Neural Computation, 11:157-192.

[10] Cardoso, J. F. and Souloumiac, A. (1993). Blind beamforming for non-gaussian signals. IEE Proceedings, 140(6):362-370. 
[11] Common, P. (1994). Independent component analysis, A new concept? Signal Processing, $36: 287-314$.

[12] Cook, K. H. and Vizy, E. K. (2016). The congobasinwalker circulation: dynamics and connections to precipitation. Climate Dynamics, 47(3):697-717. doi:10.1007/s00382-0152864-y.

[13] Dai, A., Qian, T., Trenberth, K. E., and Milliman, J. D. (2009). Changes in continental freshwater discharge from 1948 to 2004. Journal of Climate, 22(10):2773-2792. doi:10.1175/2008JCLI2592.1.

[14] de Linage, C., Famiglietti, J. S., and Randerson, J. T. (2014). Statistical prediction of terrestrial water storage changes in the Amazon Basin using tropical Pacific and North Atlantic sea surface temperature anomalies. Hydrology and Earth System Sciences, 18(6):2089-2102. doi:10.5194/hess-18-2089-2014.

[15] Dong, L., Shimada, J., Kagabu, M., and Fu, C. (2015). Teleconnection and climatic oscillation in aquifer water level inKumamoto plain, Japan. Hydrological Processes, 29(7):16871703. doi:10.1002/hyp.10291.

[16] Erfanian, A., Wang, G., and Fomenko, L. (2017). Unprecedented drought over tropical south america in 2016: significantly under-predicted by tropical sst. Scientific Reports, 7(5811). doi:10.1038/s41598-017-05373-2.

[17] Famiglietti, J. S., Cazenave, A., Eicker, A., Reager, J. T., Rodell, M., and Velicogna, I. (2015). Satellites provide the big picture. Science, 349(6249):684-685. doi:10.1126/science.aac9238.

[18] Feng, L., Hu, C., Chen, X., Li, R., Tian, L., and Murch, B. (2011). MODIS observations of the bottom topography and its inter-annual variability of Poyang Lake. Remote Sensing of Environment, 115(10):2729 - 2741. doi:10.1016/j.rse.2011.06.013.

[19] Ferreira, V., Montecino, H., Ndehedehe, C., Heck, B., Gong, Z., Westerhaus, M., and de Freitas, S. (2018). Space-based observations of crustal deflections for drought characterization in brazil. Science of The Total Environment, 644:256-273. doi:10.1016/j.scitotenv.2018.06.277.

[20] Ferreira, V. G., Montecino, H. D., Ndehedehe, C. E., del Rio, R. A., Cuevas, A., and de Freitas, S. R. C. (2019a). Determining seasonal displacements of Earth's crust in South 
America using observations from space-borne geodetic sensors and surface-loading models. Earth, Planets and Space, 71(1):84. doi:10.1186/s40623-019-1062-2.

[21] Ferreira, V. G., Ndehedehe, C. E., Montecino, H. C., Yong, B., Yuan, P., Abdalla, A., and Mohammed, A. S. (2019b). Prospects for imaging terrestrial water storage in South America using daily GPS observations. Remote Sensing, 11(6). doi:10.3390/rs11060679.

[22] Gal, L., Grippa, M., Hiernaux, P., Pons, L., and Kergoat, L. (2017). The paradoxical evolution of runoff in the pastoral Sahel: analysis of the hydrological changes over the Agoufou watershed (Mali) using the KINEROS-2 model. Hydrology and Earth System Sciences, 21(9):4591-4613. doi:10.5194/hess-21-4591-2017.

[23] Getirana, A., Kumar, S., Girotto, M., and Rodell, M. (2017). Rivers and floodplains as key components of global terrestrial water storage variability. Geophysical Research Letters, 44(20):10,359-10,368. doi:10.1002/2017GL074684.

[24] Gleick, P. H. (1989). Climate change, hydrology, and water resources. Reviews of Geophysics, 27(3):329-344. doi:10.1029/RG027i003p00329.

[25] Holland, G. J. (2009). Predicting el niño's impacts. Science, 325(5936):47-47. doi:10.1126/science.1176515.

[26] Humphrey, V., Gudmundsson, L., and Seneviratne, S. I. (2016). Assessing global water storage variability from GRACE: trends, seasonal cycle, subseasonal anomalies and extremes. Surveys in Geophysics, 37(2):357-395. doi:10.1007/s10712-016-9367-1.

[27] Huntington, T. G. (2006). Evidence for intensification of the global water cycle: Review and synthesis. Journal of Hydrology, 319(1â€“"4):83 - 95. doi:10.1016/j.jhydrol.2005.07.003.

[28] Hurkmans, R., Troch, P. A., Uijlenhoet, R., Torfs, P., and Durcik, M. (2009). Effects of climate variability on water storage in the Colorado River Basin. Journal Of Hydrometeorology, 10:1257-1270. doi:10.1175/2009JHM1133.1.

[29] Ivits, E., Horion, S., Fensholt, R., and Cherlet, M. (2014). Drought footprint on European ecosystems between 1999 and 2010 assessed by remotely sensed vegetation phenology and productivity. Global Change Biology, 20(2):581-593. doi:10.1111/gcb.12393.

[30] Jaramillo, E., Melnick, D., Baez, J. C., Montecino, H., Lagos, N. A., Acuña, E., Manzano, M., and Camus, P. A. (2017). Calibrating coseismic coastal land-level changes during the 
2014 iquique $(\mathrm{mw}=8.2)$ earthquake (northern chile) with leveling, gps and intertidal biota. PLOS One, 12(3):1-16. doi:10.1371/journal.pone.0174348.

[31] Jolliffe, I. T. (2002). Principal component analysis (second edition). Springer Series in Statistics. Springer, New York.

[32] Kao, H.-Y. and Yu, J.-Y. (2009). Contrasting eastern-pacific and central-pacific types of ENSO. Journal of Climate, 22(3):615-632. doi:10.1175/2008JCLI2309.1.

[33] Kennedy, A. M., Garen, D. C., and Koch, R. W. (2009). The association between climate teleconnection indices and Upper Klamath seasonal streamflow: Trans-niño index. Hydrological Processes, 23(7):973-984. doi:10.1002/hyp.7200.

[34] Kim, H., Yeh, P. J.-F., Oki, T., and Kanae, S. (2009). Role of rivers in the seasonal variations of terrestrial water storage over global basins. Geophysical Research Letters, 36(17):L17402. doi:10.1029/2009GL039006.

[35] Kumar, K. N., Rajeevan, M., Pai, D., Srivastava, A., and Preethi, B. (2013). On the observed variability of monsoon droughts over India. Weather and Climate Extremes, 1:42 - 50. doi:10.1016/j.wace.2013.07.006.

[36] Kummerow, C., Simpson, J., Thiele, O., Barnes, W., Chang, A. T. C., Stocker, E., Adler, R. F., Hou, A., Kakar, R., Wentz, F., Ashcroft, P., Kozu, T., Hong, Y., Okamoto, K., Iguchi, T., Kuroiwa, H., Im, E., Haddad, Z., Huffman, G., Ferrier, B., Olson, W. S., Zipser, E., Smith, E. A., Wilheit, T. T., North, G., Krishnamurti, T., and Nakamura, K. (2000). The status of the Tropical Rainfall Measuring Mission (TRMM) after two years in orbit. Journal of Applied Meteorology, 39(12):1965-1982. doi:10.1175/15200450(2001)040<1965:TSOTTR > 2.0.CO;2.

[37] Leduc, C., Favreau, G., and Schroeter, P. (2001). Long-term rise in a Sahelian watertable: the continental terminal in south-west Niger. Journal of Hydrology, 243(1-“2):43 54. doi:10.1016/S0022-1694(00)00403-0.

[38] Linage, C., Kim, H., Famiglietti, J. S., and Yu, J.-Y. (2013). Impact of pacific and atlantic sea surface temperatures on interannual and decadal variations of GRACE land water storage in tropical South America. Journal of Geophysical Research: Atmospheres, 118(19):10,811-10,829. doi:10.1002/jgrd.50820. 
[39] Lomnitz, C. (2004). Major earthquakes of Chile: A historical survey, 1535-1960. Seismological Research Letters, 75(3):368-378. doi:10.1785/gssrl.75.3.368.

[40] Lu, R. and Dong, B. (2005). Impact of atlantic sea surface temperature anomalies on the summer climate in the western North Pacific during 1997-1998. Journal of Geophysical Research: Atmospheres, 110(D16). doi:10.1029/2004JD005676.

[41] MacDonald, G. M. and Case, R. A. (2005). Variations in the Pacific Decadal Oscillation over the past millennium. Geophysical Research Letters, 32(8):L08703,. doi:10.1029/2005GL022478.

[42] Malhi, Y. and Wright, J. (2004). Spatial patterns and recent trends in the climate of tropical rainforest regions. Philosophical Transactions of the Royal Society of London, 359:311-329. doi:10.1098/rstb.2003.1433.

[43] Martinez, W. L. and Martinez, A. R. (2005). Exploratory Data Analysis with MATLAB. Computer Science and Data Analysis Series. Chapman and Hall/CRC Press LLC, UK.

[44] Montazerolghaem, M., Vervoort, W., Minasny, B., and McBratney, A. (2016). Long-term variability of the leading seasonal modes of rainfall in south-eastern Australia. Weather and Climate Extremes, 13:1 - 14. doi:10.1016/j.wace.2016.04.001.

[45] Montecino, H. D., de Freitas, S. R., Báez, J. C., and Ferreira, V. G. (2017a). Effects on chilean vertical reference frame due to the maule earthquake co-seismic and post-seismic effects. Journal of Geodynamics, 112:22 - 30. doi:10.1016/j.jog.2017.07.006.

[46] Montecino, H. D. C., Ferreira, V. G., Cuevas, A., Cabrera, L. C., Báez, J. C. S., and Freitas, S. R. C. D. (2017b). Vertical deformation and sea level changes in the coast of chile by satellite altimetry and tide gauges. International Journal of Remote Sensing, 38(24):75517565. doi:10.1080/01431161.2017.1288306.

[47] Ndehedehe, C., Awange, J., Agutu, N., Kuhn, M., and Heck, B. (2016a). Understanding changes in terrestrial water storage over West Africa between 2002 and 2014. Advances in Water Resources, 88:211-230. doi:10.1016/j.advwatres.2015.12.009.

[48] Ndehedehe, C. E. (2017). Remote sensing of West Africa's water resources using multisatellites and models. PhD thesis, Curtin University, Bentley, Perth, Western Australia. Retrieved from:http://hdl.handle.net/20.500.11937/59637 on 12th January 2018. 
[49] Ndehedehe, C. E. (2019). The water resources of tropical West Africa: propblems, progress and prospect. Acta Geophysica, 67(2):621-649. https://doi.org/10.1007/s11600-019-00260y.

[50] Ndehedehe, C. E., Agutu, N. O., Okwuashi, O. H., and Ferreira, V. G. (2016b). Spatio-temporal variability of droughts and terrestrial water storage over Lake Chad Basin using independent component analysis. Journal of Hydrology, 540:106-128. doi:10.1016/j.jhydrol.2016.05.068.

[51] Ndehedehe, C. E., Anyah, R. O., Alsdorf, D., Agutu, N. O., and Ferreira, V. G. (2019). Modelling the impacts of global multi-scale climatic drivers on hydro-climatic extremes (1901-2014) over the Congo basin. Science of The Total Environment, 651:1569 - 1587. doi:10.1016/j.scitotenv.2018.09.203.

[52] Ndehedehe, C. E., Awange, J., Kuhn, M., Agutu, N., and Fukuda, Y. (2017). Climate teleconnections influence on West Africa's terrestrial water storage. Hydrological Processes, 31(18):3206-3224. doi: 10.1002/hyp.11237.

[53] Ndehedehe, C. E., Awange, J. L., Agutu, N. O., and Okwuashi, O. (2018). Changes in hydro-meteorological conditions over tropical West Africa (1980 - 2015) and links to global climate. Global and Planetary Change, 162:321-341. doi:10.1016/j.gloplacha.2018.01.020.

[54] Ndehedehe, C. E., Awange, J. L., Corner, R., Kuhn, M., and Okwuashi, O. (2016c). On the potentials of multiple climate variables in assessing the spatio-temporal characteristics of hydrological droughts over the Volta Basin. Science of the Total Environment, 557-558:819837. doi:10.1016/j.scitotenv.2016.03.004.

[55] Ni, S., Chen, J., Wilson, C. R., Li, J., Hu, X., and Fu, R. (2018). Global terrestrial water storage changes and connections to ENSO events. Surveys in Geophysics, 39(1):1-22. doi:10.1007/s10712-017-9421-7.

[56] Nicholson, S. and Selato, J. (2000). The influence of La-Nina on African rainfall. International Journal of Climatology, 20(14):1761-1776. doi:10.1002/10970088(20001130)20:14<1761::AID-JOC580>3.0.CO;2-W.

[57] Oettli, P. and Camberlin, P. (2005). Influence of topography on monthly rainfall distribution over East Africa. Climate Research, 28(3):199-212. doi:10.3354/cr028199. 
[58] Phillips, T., Nerem, R. S., Fox-Kemper, B., Famiglietti, J. S., and Rajagopalan, B. (2012). The influence of ENSO on global terrestrial water storage using GRACE. Geophysical Research Letters, 39:L16705. doi:10.1029/2012GL052495, 2012.

[59] Rangelova, E., van der Wal, W., Braun, A., Sideris, M. G., and Wu, P. (2007). Analysis of Gravity Recovery and Climate Experiment time-variable mass redistribution signals over North America by means of principal component analysis. Journal of Geophysical Research: Earth Surface, 112(F3):2156-2202. doi:10.1029/2006JF000615.

[60] Rodell, M., Famiglietti, J. S., Wiese, D. N., Reager, J. T., Beaudoing, H. K., Landerer, F. W., and Lo, M.-H. (2018). Emerging trends in global freshwater availability. Nature, 557:651-659. doi:10.1038/s41586-018-0123-1.

[61] Ruiz, S. and Madariaga, R. (2018). Historical and recent large megathrust earthquakes in Chile. Tectonophysics, 733:37 - 56. doi:10.1016/j.tecto.2018.01.015.

[62] Salisbury, J. I. and Wimbush, M. (2002). Using modern time series analysis techniques to predict ENSO events from the SOI time series. Nonlinear Processes in Geophysics, 9(3/4):341-345. doi:10.5194/npg-9-341-2002.

[63] Save, H., Bettadpur, S., and Tapley, B. D. (2016). High-resolution CSR GRACE RL05 mascons. Journal of Geophysical Research: Solid Earth, 121(10):7547-7569. doi:10.1002/2016JB013007.

[64] Savitzky, A. and Golay, M. J. E. (1964). Soothing and differentiation of data by simplified least squares procedures. Analytical Chemistry, 36(8):1627-1639.

[65] Scanlon, B. R., Keese, K. E., Flint, A. L., Flint, L. E., Gaye, C. B., Edmunds, W. M., and Simmers, I. (2006). Global synthesis of groundwater recharge in semiarid and arid regions. Hydrological Processes, 20(15):3335-3370. doi:10.1002/hyp.6335.

[66] Scanlon, B. R., Reedy, R. C., Stonestrom, D. A., Prudic, D. E., and Dennehy, K. F. (2005). Impact of land use and land cover change on groundwater recharge and quality in the southwestern US. Global Change Biology, 11(10):1577-1593. doi:10.1111/j.13652486.2005.01026.x.

[67] Schewe, J., Heinke, J., Gerten, D., Haddeland, I., Arnell, N. W., Clark, D. B., Dankers, R., Eisner, S., Fekete, B. M., Colón-González, F. J., Gosling, S. N., Kim, H., Liu, X., Masaki, 
Y., Portmann, F. T., Satoh, Y., Stacke, T., Tang, Q., Wada, Y., Wisser, D., Albrecht, T., Frieler, K., Piontek, F., Warszawski, L., and Kabat, P. (2013). Multimodel assessment of water scarcity under climate change. PNAS, 111(9):3245-3250,. doi:10.1073/pnas.1222460110.

[68] Sheffield, J. and Wood, E. F. (2008). Global trends and variability in soil moisture and drought characteristics, 1950-2000, from observation-driven simulations of the terrestrial hydrologic cycle. Journal of Climate, 21(3):432-458. doi:10.1175/2007JCLI1822.1.

[69] Snedecor, G. W. and Cochran, W. G. (1989). Statistical methods. Iowa State University Press, 8th Edition.

[70] Sun, T., Ferreira, V. G., He, X., and Andam-Akorful, S. A. (2016). Water availability of São Francisco river basin based on a space-borne geodetic sensor. Water, 8(5).

[71] Tapley, B., Bettadpur, S., Watkins, M., and Reigber, C. (2004). The Gravity Recovery and Climate Experiment: Mission overview and early results. Geophysical Research Letters, 31:1-4. doi:10.1029/ 2004GL019920.

[72] Thomas, A. C., Reager, J. T., Famiglietti, J. S., and Rodell, M. (2014). A GRACEbased water storage deficit approach for hydrological drought characterization. Geophysical Research Letters, 41(5):1537-1545. 10.1002/2014GL059323.

[73] Tiwari, V. M., Wahr, J., and Swenson, S. (2009). Dwindling groundwater resources in northern india, from satellite gravity observations. Geophysical Research Letters, 36(18):L18401. doi:10.1029/2009GL039401.

[74] Van Loon, A. F., Kumar, R., and Mishra, V. (2017). Testing the use of standardised indices and GRACE satellite data to estimate the European 2015 groundwater drought in near-real time. Hydrology and Earth System Sciences, 21(4):1947-1971. doi:10.5194/hess21-1947-2017.

[75] Vigny, C., Socquet, A., Peyrat, S., Ruegg, J.-C., Métois, M., Madariaga, R., Morvan, S., Lancieri, M., Lacassin, R., Campos, J., Carrizo, D., Bejar-Pizarro, M., Barrientos, S., Armijo, R., Aranda, C., Valderas-Bermejo, M.-C., Ortega, I., Bondoux, F., Baize, S., Lyon-Caen, H., Pavez, A., Vilotte, J. P., Bevis, M., Brooks, B., Smalley, R., Parra, H., Baez, J.-C., Blanco, M., Cimbaro, S., and Kendrick, E. (2011). The 2010 mw 8.8 Maule megathrust earthquake of Central Chile, monitored by GPS. Science, 332(6036):1417-1421. doi:10.1126/science.1204132. 
[76] Vorosmarty, C. J., McIntyre, P. B., Gessner, M. O., Dudgeon, D., Prusevich, A., Green, P., Glidden, S., Bunn, S. E., Sullivan, C. A., Liermann, C. R., and Davies, P. M. (2010). Global threats to human water security and river biodiversity. Nature, 467:555-555-561. doi:10.1038/nature09440.

[77] Wang, S., , Huang, J., He, Y., and Guan, Y. (2014). Combined effects of the Pacific Decadal Oscillation and El Niño-Southern Oscillation on global land dry-wet changes. Scientific Reports, 4:6651. doi:10.1038/srep06651.

[78] Wang, Z., Yang, S., Lau, N.-C., and Duan, A. (2018). Teleconnection between summer NAO and East China rainfall variations: A bridge effect of the Tibetan Plateau. Journal of Climate, 31(16):6433-6444. doi:10.1175/JCLI-D-17-0413.1.

[79] Watkins, M. M., Wiese, D. N., Yuan, D., Boening, C., and Landerer, F. W. (2015). Improved methods for observing earth's time variable mass distribution with GRACE using spherical cap mascons. Journal of Geophysical Research: Solid Earth, 120(4):2648-2671. doi:10.1002/2014JB011547.

[80] Wenhaji Ndomeni, C., Cattani, E., Merino, A., and Levizzani, V. (2018). An observational study of the variability of East African rainfall with respect to sea surface temperature and soil moisture. Quarterly Journal of the Royal Meteorological Society, 144(S1):384-404. doi:10.1002/qj.3255.

[81] Westra, S., Brown, C., Lall, U., Koch, I., and Sharma, A. (2010). Interpreting variability in global SST data using independent component analysis and principal component analysis. International Journal of Climatology, 30(3):333-346. doi:10.1002/joc.1888.

[82] White, W. B., Gershunov, A., Annis, J. L., McKeon, G., and Syktus, J. (2004). Forecasting Australian drought using Southern Hemisphere modes of sea-surface temperature variability. International Journal of Climatology, 24(15):1911-1927. doi:10.1002/joc.1091.

[83] Wiese, D. N., Landerer, F. W., and Watkins, M. M. (2016). Quantifying and reducing leakage errors in the JPL RL05M GRACE mascon solution. Water Resources Research, $52(9): 7490-7502$.

[84] Wild, M., Grieser, J., and Schär, C. (2008). Combined surface solar brightening and increasing greenhouse effect support recent intensification of the global land- 
825

based hydrological cycle. Geophysical research letters, 35(L17706):L17706-1-L17706-5. doi:10.1029/2008GL034842.

[85] Wouters, B., Bonin, J. A., Chambers, D. P., Riva, R. E. M., Sasgen, I., and Wahr, J. (2014). GRACE, time-varying gravity, Earth system dynamics and climate change. Reports on Progress in Physics, 77(11):116801. doi:10.1088/0034-4885/77/11/116801.

[86] Ziehe, A. (2005). Blind source separation based on joint diagonalization of matrices with applications in biomedical signal processing. PhD thesis, Universitat Potsdam. Retrieved from:http://en.youscribe.com/catalogue/reports-and-theses/knowledge/blindsource-separation-based-on-joint-diagonalization-of-matrices-1424347. Accessed 15 May 2015. 